\title{
Detection of chlamydial antibodies in women with pelvic inflammatory disease and infertility
}

\author{
Ramona Perhar, Shilpi Rawat, Ruchi Pandey \\ Correspondence: Dr Shilpi Rawat, Senior Resident Depatment of Obs \& Gynae, MLN \\ Medical College Allahabad; Email - drshilpirawat08@gmail.com
}

Distributed under Attribution-Non Commercial - Share Alike 4.0 International (CC BY-NC-SA 4.0)

\begin{abstract}
Objective: To detect the chlamydial antibodies in women with pelvic inflammatory disease (PID) and infertility. Method: This study was carried out on 72 patients suffering from pelvic inflammatory disease and/ or infertility who were admitted in the indoor wards and those attending the out patient department. Control group comprised of relatives of patients, nursing staff and other staff of the hospital who did not have any present or past history of PID or infertility. Result: IgG and IgA antibodies were detectable in 50\% cases of PID while IgG alone were detectable in $75 \%$ cases of PID. Compared with the control group, the differences was statistically significant (p value $<0.001)$. Statistically significant $(\mathrm{p}<0.001)$ chlamydial IgG antibodies among the infertile subjects with fallopian tube disorders was found compared to the infertile subjects with normal tubes. IgG antibodies Chlamydia were positive in 1:64 dilution in 75\% cases of PID and IgA antibodies Chlamydia were positive in 1:16 dilution in $50 \%$ cases of PID. Assay for IgG in infertile women, $10 \%$ cases were positive at $1: 128$ dilution. Ten $(33.33 \%)$ cases of infertility were positive for IgA antibodies (1:16dilution). Results are statistically significant as compared to control group ( $p$ value $<0.001)$. Conclusion: It appears that testing for IgG antibodies at a serum dilution of 1:64 and for IgA antibodies at a dilution of 1:16 by the IPA test comprises the best combination for the differentiation between the PID patients and apparently healthy controls, and it is suggested that this be used as a marker of active $\mathrm{C}$. trachomatis infection.
\end{abstract}

Keywords: Chlamydia antibody, infertility, PID.

In the early $1900^{\text {ee }}$ E European researchers realized that the various type of blood cells e.g. white blood cells, red blood cells and platelets all came from a particular stem cell. Stem cells have an amazing ability to create different kinds of tissues when they divide and develop ${ }^{1}$. Cord blood is the blood from the baby that is left in the umbilical cord and placenta after birth. It contains special cells called hematopoietic stem cells. Chlamydia trachomatis infection is one of the most prevalent sexually transmitted diseases in the world ${ }^{1}$. C. trachomatis is a common cause of pelvic inflammatory disease (up to $40 \%$ ). Almost $80 \%$ of cases are asymptomatic, this leads to continued transmission of the infection to sexual partners and the opportunity for chronic infection ${ }^{2,3}$. Few women with $\mathrm{C}$. trachomatis in the lower genital tract will progress to frank PID ${ }^{4}$. Most infected women will spontaneously clear their infections. Women who do not clear their infections may suffer ascending infection and

Received: $22^{\text {nd }}$ August 2019. Accepted: $8^{\text {th }}$ November 2019.

Perhar R, Rawat S, Pandey R. Detection of chlamydial antibodies in women with pelvic inflammatory disease and infertility. The New Indian Journal of OBGYN. 2020; 6(2): 101-5. 
expansion into the full PID syndrome ${ }^{5,6}$.

Laboratory cell culture support a higher level or predominance of a Th1 of immune response to chlamydial infection, with IFN-y, IL-8, IL-1, and IL-6 findings featuring almost universally in the studies (although IFNy was also associated with protection against a repeat infection). Recently, direct fluorescent antibody tests and enzyme immunoassays for the rapid diagnosis of $\mathrm{C}$. trachomatis infection have been introduced, but their sensitivities and specificities vary considerably ${ }^{7-9}$. PCR is reported to be the most sensitive method for detecting C. trachomatis infection ${ }^{10}$. Evaluation of tubal infertility may include serological antibody studies, hystero salpingography and laparoscopy ${ }^{11-13}$. This study aims to detect the chlamydial antibodies in women with pelvic inflammatory disease (PID) and infertility.

\section{Materials and methods}

The present study was carried out on 72 patients suffering from pelvic inflammatory disease and/ or infertility who were admitted in the indoor wards and those attending the out patient department (OPD) of Gayatri Hospital Allahabad after taking consent and approved by ethics committee. "Study group" comprised of patients attending Gynae OPD and admitted in Gynae ward suffering from PID or infertility and "Control group" comprised of relatives of patients, nursing staff and other staff of the hospital who did not have any present or past history of PID or infertility.

Following data was collected from every subject suffering from PID -

- Personal data

- Chief presenting complaints and their duration.

- Detailed history specially $\mathrm{h} / \mathrm{o}$

- Fever

- Pain in lower abdomen

- Chronic backache

- Discharge per vaginum

- Menstrual irregularity

- Dyspareunia

- Dysmenorrhoea

General and systemic examination was done along with perspeculum examination to see any sign of inflammation and discharge. Pervaginum examination was done to look especially for tenderness in fornices, adnexa palpable or not, if palpable tender or not and fixed retroversion of uterus.

Data collected from patients suffering from infertility were personal data, duration of marriage, any history suggestive of PID. General, systemic and local examination was done to rule out any obvious cause (other than PID) of infertility.

The subjects of study were classified in three groups 1) Pelvic inflammatory disease (32 cases), 2) Infertility (30 cases), 3) Healthy control (10 cases). Both study and control groups were well matched with respect to their age, parity and socioeconomic status. All the controls and cases were subjected to -

1. Complete haemogram - $\mathrm{Hb} \%$, TLC, DLC, ESR

2. Urine examination - routine, microscopic

3. Urine culture and sensitivity wherever needed

4. Blood sugar examination - Fasting, post parandial

5. VDRL

6. X - ray chest - to rule out tuberculosis

7. Husband seminogram

8. Premenstrual endometrial biopsy in case of

9. Diagnostic laproscopy and infertility only chromotubation

10. Specific diagnostic test - Immunoperoxidase assay (IPA) to detect IgG and IgA antibodies against Chlamydia trachomatis. The IPAzyme Chlamydia test is a novel indirect immunoperoxidase assay using $C$. trachomatis serotype L2-infected cells as the antigen for the detection of serum $\operatorname{IgG}$ and $\operatorname{IgA}$ antibodies. The blood was collected aseptically about $1 \mathrm{cc}$ in amount on the day they reported to the hospital. The serum was separated and stored at $2-8^{0} \mathrm{C}$ with $0.2 \%$ sodium azide as preservative. It was tested within a few days. Only clear and non haemolytic serum samples were used. IPA was performed at the microbiology department of S.V.B.P. hospital, Meerut following the procedure of Bhujwala et $\mathrm{al}^{14}$. For each serum sample, a dilution of 1:16 for the IPAzyme IgA assay and dilutions of 1:64 and 1:128 for the $\operatorname{IgG}$ assay were prepared. The IPAzyme Chlamydia assay was performed according to the manufacturer's instructions.

\section{Results}

As shown in table 1, both IgG and IgA antibodies were detectable in $50 \%$ cases of PID (16 out of 32 ) while IgG alone were detectable in $75 \%$ cases of PID (24 out of 32 ). In control group no cases showed IgG for Chlamydia 
Table 1: Positivity of indirect immunoperoxidase assay (IPA) for different antibodies against Chlamydia

\begin{tabular}{lllll}
$\begin{array}{l}\text { Group } \\
\text { of cases }\end{array}$ & $\begin{array}{l}\text { No of } \\
\text { cases }\end{array}$ & $\begin{array}{l}\text { Only IgG } \\
+\end{array}$ & $\begin{array}{l}\text { Both IgG and } \\
\text { IgA+ } \\
\text { No (\%) }\end{array}$ & $\begin{array}{l}\text { Only } \\
\text { IgA }+\end{array}$ \\
\hline PID & 32 & $24(75 \%)$ & $16(50 \%)$ & - \\
Control & 10 & 0 & 0 & 0 \\
\hline
\end{tabular}

as compared to PID group having $75 \%$ positivity rate. Compared with the control group, the differences were statistically significant ( $\mathrm{p}$ value $<0.001$ ). Indirect immune compared to the infertile subjects with normal tubes $(25.0 \%)$. The differences were statistically significant ( $p$ $<0.001$ ) between these groups. Similar statistically significant differences in prevalence of $\operatorname{IgG}$ (at 1:128 dilution) and $\operatorname{IgA}$ were observed between the various subgroups of infertile women.

The highest recall frequency of previous PID was demonstrated among the infertile women with tubal occlusion (group C) $35.29 \%$ as compared with the

Table 2: IPA positivity for antichlamydial IgG and IgA antibodies in cases of PID at different dilution of patients serum

\begin{tabular}{|c|c|c|c|c|c|c|}
\hline \multirow[t]{2}{*}{ Groups } & \multicolumn{2}{|c|}{ Ig A (1:16dilution)positive cases } & \multicolumn{2}{|c|}{ Ig G (1:64 dilution)positive cases } & \multicolumn{2}{|c|}{ Cases $1: 128$ dilution } \\
\hline & No. & $\%$ & No. & $\%$ & No. & $\%$ \\
\hline PID & 16 & $50.0 \%$ & 24 & 75 & 8 & 25 \\
\hline Control & - & - & - & 0 & - & - \\
\hline
\end{tabular}

peroxidise assay was done at different dilution indicates that IgG antibodies Chlamydia were positive in 1:64 dilution in $75 \%$ cases of PID (24 out of 32 ), $25 \%$ ( 8 out of 32) cases were positive in 1:128 dilution too. Where as in the control group no cases was positive for $\operatorname{IgG}$ at 1:64

infertile women with normal tubal (group A). The differences were statistically significant $(p<0.001 \%)$. The prevalence of IgG antibody among these women with a past history of PID was $85.71 \%$ (6 out of 7 ) compared with the $56.52 \%$ (13 out of 23 ) among the women who

Table 3: Prevalence of IgG and IgA antibodies to Chlamydia trachomatis in fertile women and recall frequency of pelvic inflammatory disease within different groups of women versus control group.

\begin{tabular}{|c|c|c|c|c|c|}
\hline \multirow[t]{4}{*}{ Group } & \multirow{4}{*}{$\begin{array}{l}+ \text { ve cases /total } \\
\text { cases } \\
\text { No }(\%)\end{array}$} & \multicolumn{3}{|c|}{ Chlamydial serology } & \multirow{4}{*}{$\begin{array}{l}\text { Recall } \\
\text { of PID } \\
\text { No (\%) }\end{array}$} \\
\hline & & IgG+ & IgG + & $\operatorname{IgA}+$ & \\
\hline & & $1: 64$ & $1: 128$ & $1: 16$ & \\
\hline & & No(\%) & No $(\%)$ & No $(\%)$ & \\
\hline 1.control & $0 / 10$ & 0 & Nil & Nil & Nil \\
\hline 2.Infertility & $19 / 30(63.33 \%)$ & $19(63.33 \%)$ & $3(10 \%)$ & $10(33.33 \%)$ & $7(23.33 \%)$ \\
\hline A)Normal tubes & $2 / 8(25 \%)$ & $2(25 \%)$ & Nil & Nil & Nil \\
\hline B)Tubal adhesions & $3 / 5(60 \%)$ & $3(60 \%)$ & Nil & $1(20 \%)$ & $1(20 \%)$ \\
\hline C)Tubal blockade & $14 / 17(82.35 \%)$ & $14(82.35 \%)$ & $14(82.35 \%)$ & $9(52.94 \%)$ & $6(35.29 \%)$ \\
\hline
\end{tabular}

dilution and therefore none at 1:128 dilution or for IgA (table 2). The differences were statistically significant $(\mathrm{p}$ value $<0.001)$. As shown in the table $3,63.33 \%$ cases of infertility showed positive indirect immunoperoxidase assay for IgG at 1:64 dilution (19 out of 30 cases) while only $10 \%$ cases (3out of 30 cases) were positive at 1:128 dilution. Ten $(33.33 \%)$ cases of infertility were positive for IgA antibodies (1:16dilution). Results were statistically significant as compared to control group ( $\mathrm{p}$ value $<0.001$ ).

The table also depicts statistically significant $(p<0.001)$ higher prevalence of chlamydial IgG antibodies among the infertile subjects with fallopian tube disorders $(82.35 \%)$ in group B and $(60.0 \%)$ in group C, as recalled no PID history .The differences observed was significant.

\section{Discussion}

All the study group were subjected to indirect immunoperoxidase assay which provides detection of specific IgG and IgA antibodies against C. Trachomatis in sera of patients. For the diagnostic of Chlamydia antibodies IPAzyme test can be used specially to detect cases of PID which is a major problem in India. In total $75 \%$ cases of PID (24 out of 32 ) were positive for IgG in $1: 64$ dilution while only $25 \%$ ( 8 out of 32 ) were positive for $\operatorname{IgG}$ in $1: 128$ dilution. IgA in 1:16 dilution was detected in $50 \%$ (16 out of 32 ) cases of PID but no case 
was positive for $\operatorname{IgA}$ alone in the absence if $\mathrm{IgG}$ for

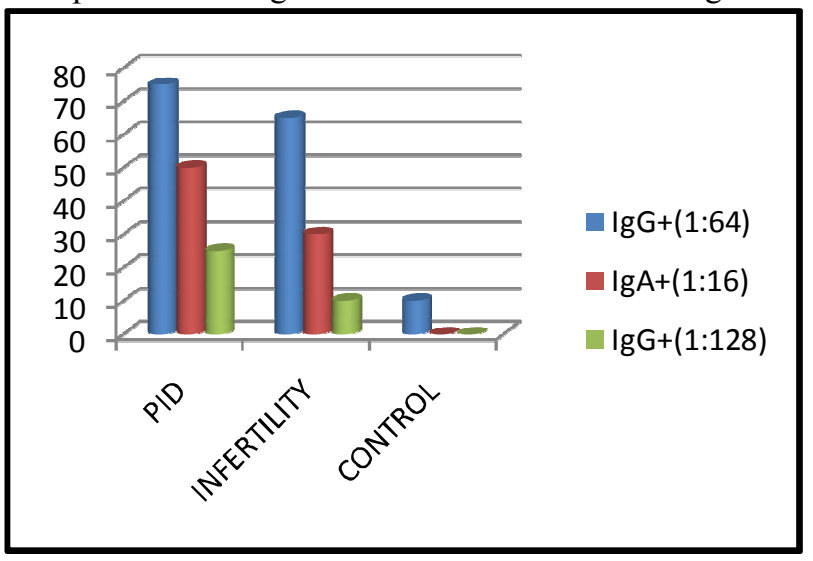

Figure 1: Frequency distribution of antibody response to C. Trachomatis infection measured by immuneperoxidase assay in different clinical categories

Chlamydia. In contrast control group showed positive result in none of the 10 cases even for $\operatorname{IgG}$ at 1:64 dilution (Figure 1). The differences in the two groups are statistically significant.

In our study 30 cases of infertility were also included and were divided into three subgroups according to macroscopic appearance of fallopian tubes seen on diagnostic laproscopy and chromotubation. The control group included 10 healthy persons having no fertility problem or any other disease of genitor urinary tract. The study shows that $8 / 30(26.7 \%)$ had normal tubes while $5 / 30(16.7 \%)$ had peritubal adhesions without tubal blockade while $17 / 30(56.7 \%)$ had unilateral or bilateral tubal blockade. These figures confirm the findings of Arye Hurwitz and associates ${ }^{15}$ who also demonstrated tubal factor as an important factor in etiology of infertility.

As the table 3 shows much higher prevalence of antichlamydial antibodies in patient with tubal disease (60\% in patients with tubal adhesions and $82.33 \%$ in patients with tubal blockade vs $25 \%$ in patients with normal tubes), it suggests that high prevalence of $\mathrm{C}$. Trachomatis antibody among infertile women with tubal disease and a low prevalence of antibody among infertile women without tubal disease therefore indicating that Chlamydia is responsible for a considerable proportion of tubal infertility.
In our study women with only peritubal adhesions had a lower prevalence of antibody than did women with distal occlusion ( $60 \%$ vs $82.35 \%)$ perhaps because peritubal adhesions without tubal obstruction are due to a mild infection which causes slight antibody stimulation or because they are non infectious in origin. The serological test is rapid and non invasive, and our data suggests that it would be useful in investigation of infertility.

\section{Conclusion}

Immunoperoxidase assay is a non invasive, easy and reliable test for diagnosis of chlamydial infection of genital tract. The availability of serologic marker for $\mathrm{C}$. Trachomatis reduces the necessity for invasive procedure for diagnosis, the test can be employed for early detection of this infection, so that the timely treatment can prevent the disease from damaging the upper genital tract.

\section{Conflict of interest: None. Disclaimer: Nil.}

\section{References}

1. Malhotra M, Sood S, Mukherjee A, Muralidhar S, Bala M. Genital Chlamydia trachomatis: An update. Indian J Med Res. 2013 Sep; 138(3): 303-16.

2. Soper DE. Pelvic inflammatory disease. Obstet Gynecol. 2010; 116(2 Pt 1): 419-28.

3. Soper DE, Brockwell NJ, Dalton HP. Microbial etiology of urban emergency department acute salpingitis: treatment with ofloxacin. American Journal of Obstetrics and Gynecology. 1992;167(3): $653-60$

4. Gottlieb SL, Martin DH, Xu F, Byrne GI, Brunham RC. Summary: the natural history and immunobiology of Chlamydia trachomatis genital infection and implications for chlamydia control. Journal of Infectious Diseases. 2010; 201(suppl 2): S190-S204.

5. Oakeshott P, Kerry S, Aghaizu A, Atherton H, Hay S, Taylor-Robinson D, et al. Randomised controlled trial of screening for Chlamydia trachomatis to prevent pelvic inflammatory disease: the POPI (prevention of pelvic infection) trial. BMJ. 2010; 340: c1642.

6. Geisler WM. Duration of untreated, uncomplicated Chlamydia trachomatis genital infection and factors associated with Chlamydia resolution: are views of 
human studies. J Infect Dis. 2010; 201 (Suppl 2): S104-13

7. Gann PH, Herrmann JE, Candib L, Hudson RW. Accuracy of Chlamydia trachomatis antigen detection methods in a low-prevalence population in a primary care setting. J Clin Microbiol. 1990; 28:1580-5.

8. Schwebke JR, Stamm WE, Hansfield HH. Use of sequential enzyme immunoassay and direct fluorescent antibody tests for detection of Chlamydia trachomatis infections in women. J Clin Microbiol. 1990; 28: 2473-6.

9. Tjiam KH, van Heijst YM, van Zuuren A, Wagenvoort JHT, van Joost T, Stolz E, et al. Evaluation of an enzyme immunoassay for the diagnosis of chlamydial infections in urogenital specimens. J Clin Microbiol. 1986; 23:752-4.

10. Ossewaarde JM, Rieffe M, Rozenberg-Arska M, Ossenkoppele PM, Nawrocki RP, van Loon AM. Development and clinical evaluation of a polymerase chain reaction test for detection of Chlamydia trachomatis. J Clin Microbiol. 1992; 30:2122-8.

11. Perquin DA, Beersma MFC, de Craen AJM, Helmerhorst FM. The value of Chlamydia trachomatis-specific IgG antibody testing and hysterosalpingography for predicting tubal pathology and occurrence of pregnancy. Fertility and Sterility. 2007; 88(1): 224-6.

12. Keltz MD, Gera PS, Moustakis M. Chlamydia serology screening in infertility patients. Fertil Steril. 2006; 85(3): 752-4.

13. Rodgers AK, Wang J, Zhang Y, Holden A, Berryhill B, Nicole M, et al. Association of tubal factor infertility with elevated antibodies to Chlamydia trachomatis caseinolytic protease $\mathrm{P}$. American Journal of Obstetrics and Gynecology. 2010; 203(5): 494.e7-494.e14.

14. Bhujwala RA, Amatya S, Bhargava VL, Sengupta S. Chlamydia trachomatis in pelvic inflammatory disease. The Indian Journal of Medical Research. 1991; 93: 359-63

15. Hurwitz A, Laufer N, Keshet I, Rabinowitz R, Lewin A, Palti Z, et al. The effect of insulin on progesterone production and cellular growth in long-term cultures of human granulosa lutein cells. Fertility and Sterility. 1987; 48(5): 791-95.

\footnotetext{
Ramona Perhar ${ }^{1}$, Shilpi Rawat ${ }^{2}$, Ruchi Pandey ${ }^{3}$

${ }^{1}$ Lecturer, Ex associate Professor; ${ }^{2}$ Senior Resident;

${ }^{3}$ Junior Resident, Depatment of Obs \& Gynae MLN

Medical College Allahabad
} 